IZA DP No. 8348

\title{
Season of Birth and Marital Outcomes
}

Sonia Oreffice

July 2014 


\title{
Season of Birth and Marital Outcomes
}

\author{
Sonia Oreffice \\ University of Surrey \\ and IZA
}

\section{Discussion Paper No. 8348 \\ July 2014}

\author{
IZA \\ P.O. Box 7240 \\ 53072 Bonn \\ Germany \\ Phone: +49-228-3894-0 \\ Fax: +49-228-3894-180 \\ E-mail: iza@iza.org
}

\begin{abstract}
Any opinions expressed here are those of the author(s) and not those of IZA. Research published in this series may include views on policy, but the institute itself takes no institutional policy positions. The IZA research network is committed to the IZA Guiding Principles of Research Integrity.

The Institute for the Study of Labor (IZA) in Bonn is a local and virtual international research center and a place of communication between science, politics and business. IZA is an independent nonprofit organization supported by Deutsche Post Foundation. The center is associated with the University of Bonn and offers a stimulating research environment through its international network, workshops and conferences, data service, project support, research visits and doctoral program. IZA engages in (i) original and internationally competitive research in all fields of labor economics, (ii) development of policy concepts, and (iii) dissemination of research results and concepts to the interested public.
\end{abstract}

IZA Discussion Papers often represent preliminary work and are circulated to encourage discussion. Citation of such a paper should account for its provisional character. A revised version may be available directly from the author. 


\section{ABSTRACT}

\section{Season of Birth and Marital Outcomes}

This study analyzes the marriage-market aspects of season of birth in the United States, estimating whether and how marital status is related to quarter of birth by gender and race, also incorporating cohabitation as a separate relationship status. For couples, additional analysis considers who is matched with whom and the spousal (partner's) trade-offs of quarters of birth and socioeconomic attributes. Using the American Community Survey data 2010-2012, I show that white women born in the fourth quarter are more likely to be married than never married (marriage more likely than cohabitation), while never married white men from the second birth quarter are less likely to be cohabiting than single. Black men from the first birth quarter are less likely to be married rather than cohabiting but more likely to be cohabiting than single. White women from the third birth quarter and black women from the second are more likely to be divorced, always controlling for demographic and socioeconomic characteristics. Among white married couples, men born in the first quarter have more educated and richer wives, and conversely women from the same first quarter have less educated husbands. In cohabiting couples, white men and women born in the third quarter have richer and less educated partners, respectively, and black women from the first quarter have poorer partners. Finally, in all types of couples, black women born in the fourth quarter have richer husbands.

JEL Classification: D1, J1

Keywords: quarter of birth, marriage, cohabitation, divorce, single, marriage market

Corresponding author:

Sonia Oreffice

School of Economics

University of Surrey

Guildford, Surrey, GU2 7XH

United Kingdom

E-mail: s.oreffice@surrey.ac.uk

\footnotetext{
*Financial support from the Spanish Ministry of Science and Innovation (ECO 2011-29751/ECON) and the University of Surrey is acknowledged. I would like to thank Climent Quintana-Domeque for helpful comments and suggestions and Paraskevas Kipouros for table formatting. Any errors are mine.
} 


\section{Introduction}

This paper explores the associations between season of birth and marital outcomes such as marital status, type of relationship and spousal (partner's) characteristics. Specifically, this study investigates whether quarter of birth is a determinant of being married, divorced or never married, and of being married rather than cohabiting or single, also analyzing the spousal (partner's) trade-offs between season of birth and socioeconomic attributes. It examines the extent to which these associations of season of birth and marital outcomes vary by race and gender, estimating these marital and sorting patterns with the American Community Survey data for 2010-2012, i.e., the largest and most recent nationally representative sample of individuals for whom we have detailed demographic and socioeconomic information.

Existing research on the link between season of birth and later outcomes focuses on socioeconomic, physical or psychiatric outcomes. For instance, in the medical literature evidence has emerged on the impact of season of birth on psychiatric and neurological disorders, physical and cognitive development such as height, schizophrenia, sports performance, with different quarters of birth affecting different types of outcomes. In economics, since the seminal work by Angrist and Krueger (1991) showed that season of birth is related to educational attainment, ${ }^{1}$ season of birth became popular in studies of education and earnings based on its believed exogeneity. However, since Bound and Jaeger (1996) several economic studies questioned this assumption by unveiling channels through which season of birth may ultimately affect socioeconomic outcomes. For instance, Buckles and Hungerman (2013) emphasize the role of maternal characteristics in shaping the later socioeconomic disadvantage of winter-born individuals, whereas Currie and Schwandt (2013) explain the same first quarter of birth

\footnotetext{
${ }^{1}$ Negative effect of first quarter of birth found on high-school graduation rates due to compulsory school leaving age rules.
} 
disadvantage through the negative impact on birth weight and gestational weeks of the disease environment in cold months.

Overall, explaining the underlying nature and mechanisms of these season of birth effects in terms of which genes, environment, or behavior are involved remains a challenging task and open question (Disanto et al., 2011; McGrath et el., 2006; Tonetti, Fabbri, Natale, 2009; Weber, Prossinger, Seiger, 1998).

At the same time, a large body of recent empirical literature strongly suggests that individual attributes besides socioeconomic status affect marriage probabilities and shape matching patterns (Averett, Sikora, Argys, 2008; Lundberg, 2012; Malcolm and Kaya, 2014), and that spouses (partners) tend to sort also by physical and psychological traits such as body mass index, height, personality, and risk attitudes (Chiappori, Oreffice and Quintana-Domeque, 2012; Dupuy and Galichon, 2014; Oreffice and Quintana-Domeque, 2010; Spivey, 2010).

However, neither of these strands of literature on season of birth and later outcomes or on matching in the marriage market examined the link between season of birth and the marriage market, although marital and sorting patterns represent major outcomes in an individual's adult life and have direct demographic consequences. The aim of this paper is to document these associations, estimating the impact of season of birth on household formation and dissolution and the extent of these marital and sorting patterns by race and gender, controlling for a variety of individual and spousal (partner's) characteristics. In other words, this analysis asks what is the empirical content (if any) left in quarter of birth once the standard socioeconomic characteristics are controlled for, and it is strengthened by the fact that season of birth is an individual trait that is totally time-invariant and clearly pre-determined with respect to marital status and 
socioeconomic status, which is not necessarily the case for other non-socioeconomic characteristics.

More generally, this study fits into a growing literature on the effects of heterogeneity in psychological traits on demographic decisions and behaviour, which encompasses economics and other social sciences. The existing literature has mainly focused on socioeconomic attributes, while little attention has been devoted so far to physical and psychological traits and preferences. US Population Census data are used, specifically the American Community Survey for the years 2010, 2011, and 2012, which represent a one-percent national random sample of the population and provide the most recent and the largest sample of detailed demographic and socioeconomic information on individuals and their spouses (partners) in the US. In particular, these data provide quarter of birth information for each individual and his/her marital status, but they also allow identification of spouses and unmarried partners so that the latter can be distinguished from single individuals not in a relationship. Age, educational attainment, a dummy for being Hispanic, number of young children and annual earnings are also accounted for. I consider the sample of black and white men and women aged 25-45 who are married in their first marriage, never married (cohabiting or single), or divorced, restricting the analysis to US-born individuals in order to avoid potential confounding heterogeneous effects of birth seasonality at other latitudes and hemisphere that may be linked to very different temperatures, disease environments and culture.

Empirical analysis on individual marital outcomes reveals that white women born in the fourth quarter are more likely to be married than never married, and that this significant difference is driven by the fourth quarter influencing the type of relationship (marriage more likely than cohabitation) rather than the odds of being married instead of single. Conversely, never married 
white men from the second birth quarter are less likely to be cohabiting than single, showing that for white men early season of birth is related to being or not in a couple rather than to the type of relationship. Black men from the first quarter are less likely to be married rather than cohabiting but more likely to be cohabiting than single, so that for black men early season of birth decreases the odds of being married. No such patterns are found for black women. In terms of family dissolution, white women from the third birth quarter and black women from the second are more likely to be divorced.

As to matching patterns, in white married couples men born in the first quarter have more educated and richer wives than other white men do, and conversely women from the same first quarter have less educated husbands than other white women do. Among cohabiting couples, white men and women born in the third quarter have richer and less educated partners, respectively, and black women from the first quarter have poorer partners. Finally, in all types of couples, black women born in the fourth quarter have richer husbands than other black women do.

These findings represent the first empirical support for season of birth to influence marital outcomes, with earlier quarters of birth affecting male outcomes and later quarters of birth affecting female ones, in terms of family formation and spousal trade-offs with socioeconomic characteristics, with interesting differences by gender and race. It is reassuring that the above evidence on black men and women is consistent with the well-known marriage market patterns of blacks in the US, i.e., the absence of a significant impact of season of birth on marital outcomes for black women is consistent with black females being in extreme excess supply, whereas the impact on black men is consistent with them being in very short supply and the more 
attractive ones favoring cohabitation rather than marriage (Banks, 2011; Becker, 1991; Neal, 2004; Wilson, 1987).

The season of birth differences by gender, estimated controlling for cohort and socioeconomic status, seem to suggest an interpretation of gender disparity in attractiveness in the marriage market. If we accept that physical attributes affect female attractiveness and men value youth, physical appearance and younger perceived age, while being relatively older and mature enhances male attractiveness and "reproductive success" (Huber et al., 2004; GrossbardShechtman, 1993; Oreffice and Quintana-Domeque, 2010, Townsend and Wasserman, 1998), then the estimated season of birth patterns in marital outcomes may reflect individual attractiveness. Those women born in the fourth quarter are relatively younger and perceived age may provide a better indication of biological age than chronological age, so that the estimated fourth quarter marriage premium may reflect preferences for more (physically) attractive women, with no marriage premium for stronger or taller women (traits associated with earlier birth quarters), whereas older, stronger, more confident and reproductively successful men (earlier birth quarters) are more likely to be in a relationship and have better spouses (Case and Paxson, 2008; Hitsch, Hortaçsu, Ariely, 2010; Huber et al., 2004; Grossbard-Shechtman, 1993; Oreffice and Quintana-Domeque, 2010; Townsend and Wasserman, 1998).

Alternative explanations are considered also in light of the existing literature on season of birth effects on health, personality and socioeconomic factors. However, these phenomena do not provide an adequate explanation for the above empirical evidence on marital outcomes and sorting patterns, also because the latter varies specifically by gender and race, whereas the existing literature does not and concerns different quarters. 
This paper represents the first systematic analysis of season of birth and marital outcomes, beyond its impact on education or earnings that has been traditionally emphasized in economics. This evidence hopefully represents a step toward a comprehensive understanding of the imprint that season of birth seems to give to individual life and wellbeing, which remains a challenge across disciplines due to the variety of life aspects and individual outcomes that season of birth can potentially affect, which influence and mechanisms are still unexplored.

The paper is organized as follows. Section 2 describes the empirical specification and the data. Section 3 presents the empirical results. Section 4 considers alternative explanations for the findings. Section 5 concludes the paper.

\section{Empirical Specification and Data Description}

Estimation is carried out on US Population Census data, specifically on the most recent waves of the American Community Survey, i.e., 2010, 2011, 2012. These cross-sectional data represent one-percent samples of the US population and allow to identify the quarter of birth of each individual and his/her martial history in terms of order (number of marriages) and year of current marriage, in addition to detailed demographic and socioeconomic information at the household and individual level. Using the variable "relationship to household head", all individuals who are household heads, spouses or unmarried partners are extracted to create the large sample of individuals of all marital stata on which to analyze how season of birth is linked to marital outcomes; furthermore, those individuals whose "relationship to head" is specified as "spouse" or "unmarried partner" are then matched to the corresponding "household head" on the household identification code "serial". As such, it is also possible to distinguish unmarried individuals who are single (not in a relationship) from those who are cohabiting with an 
unmarried partner, where an unmarried partner is defined to "share living quarters and have a close personal relationship with the householder" (2000 Census Documentation B14 and B63). In the following empirical analysis "single" will be used for "not in a relationship", and this status can be distinguished from the marital status "never married", since the latter encompasses both single individuals and those who are cohabiting with an unmarried partner. It is important to note that cohabitation is incorporated here as a separate relationship status from both marriage and singlehood, and this generates additional interesting comparisons.

Using this information, I also create two additional samples of couples, married couples and cohabiting unions, with a single observation for each couple, which are used to understand the sorting and matching patterns by season of birth and socioeconomic status, in the population of both married and cohabiting individuals. Individuals with imputed values for sex, marital status or relationship to household head are excluded from the analysis along with those who are in the military, in farm households, or still in school.

To capture the marriage-market aspects of season of birth I construct the following set of individual marital outcomes: dummy variable indicator of being married rather than never married, dummy variable of being married versus single, dummy variable of being married versus cohabiting, and dummy variable of being cohabiting versus single, to ascertain how the difference between married and never married may be due to being in a relationship or not rather than to being legally married per se. To be able to measure the link of season of birth with family dissolution I also generate dummy variables for being divorced rather than married, for being divorced rather than never married, or single, or cohabiting.

The key explanatory variable of interest is quarter of birth (January-March, April-June, JulySeptember, October-December), i.e., four dummy variables one for each quarter of birth, while 
age, educational attainment, a dummy for being Hispanic, number of own children age 4 and under residing in the household and annual earnings are also considered. State and year fixed effects are included, and heteroskedasticity robust standard errors are used. Finally, individual weights are employed to make the sample representative of the US population.

Binomial logistic regressions of the above marital indicators are estimated to measure the link between quarter of birth and individual marital outcomes, while OLS regressions of years of education or annual earnings are run to estimate the spousal (partner's) trade-offs between season of birth and socioeconomic attributes, i.e., the extent of marital sorting by season of birth within married and cohabiting couples.

The main analysis considers black and white men and women who are US-born, in their first marriage if married at all, and between 25 and 45 years of age, to keep uniform reference groups with respect to marital outcomes. The restriction on place of birth is prompted by the fact that season of birth for foreign-borns may be related to very different temperatures, disease environment and culture from the US, and therefore the link with season of birth and later outcomes may be altered for them. Finally, observations are restricted to those individuals who have at least the fifth grade and are above the $1 \%$ of household income.

Table 1 presents the descriptive statistics for individuals, married couples, and cohabiting couples, separated by race. Table 1a shows that among whites, women are more likely to be married, are more educated and earn less than men, that those in a couple are younger and earn even less than their male mates, and that partners in cohabiting couples are much younger, less educated, and earn less than married people, on average. Table $1 \mathrm{~b}$ provides a similar picture for the black sample in terms of age, education and earnings, with the interesting twist that among 
blacks, it is men who are more likely to be married or cohabiting than never married, which is consistent with the strong marriage market imbalance that characterizes them.

[Table 1a about here]

[Table $1 \mathrm{~b}$ about here]

The Tables $1 \mathrm{a}$ and $1 \mathrm{~b}$ also show that births are evenly distributed across quarters, with a slightly higher prevalence of Summer births, and the distribution is symmetric by gender. For black individuals, a slight pike is registered in the first quarter, again with no gender differences and an even distribution, as it has been reported in the literature, e.g., in Buckles and Hungerman (2013).

\section{Results}

\subsection{Individual marital outcomes}

Family formation. Table 2 presents the binomial logistic regressions of the dummy variable for being married rather than never married on quarter of birth indicators (the first quarter is the omitted category) and other individual characteristics, estimated separately by gender and race. Three specifications are presented for each regression: a standard one controlling for age, state and year fixed effects, an augmented one that also controls for education and a dummy variable for being Hispanic, and a fully augmented one that additionally controls for earnings and number of young children.

[Table 2 about here]

Panel A shows that white women born in the fourth quarter are significantly more likely to be married instead of never married, that is, the odds of being married if born in the fourth quarter are 1.04 times higher than if born in other quarters (exp of .040), and this is significant at the $1 \%$ 
level in the fully augmented specification (column 3). That is, a later quarter of birth increases the marriage probability, and this represents a sizable impact of season of birth on marriage odds: in comparison, the marriage odds ratio for one more year of education is 1.08 (exp of .075), and in column 2 the odds for the fourth quarter of birth and education actually coincide. It is reassuring that all other controls exhibit the expected signs and associations with being married and the estimated coefficients are very similar across specifications, indicating that the results are unlikely to be driven by omitted variable bias or by socioeconomic attributes affecting marriage. I then report the same empirical analysis for white men (columns 4-6). The corresponding coefficients do not exhibit any significant association of season of birth with probability of being married, and their size is very small taking their exponential and none of them is statistically different from one.

Panel B reports the corresponding empirical evidence for black men and women, showing that for them quarter of birth does not affect an individual's probability of being married rather than never married, regardless of gender.

A distinctive feature of the above analysis of birth seasonality on marriage outcomes is that the dependent variable compares the two marital stata of being married and never married, not allowing to disentangle the marriage market outcome of being in a relationship from the type of relationship an individual is involved in. To explore potential heterogeneous effects along the type of relationship, Table 3 presents the results of several logistic regressions on quarter of birth indicators, age, education and a dummy for being Hispanic, ${ }^{2}$ where the dependent variables focus in turn on being married versus never married single, on being married versus never married

\footnotetext{
${ }^{2}$ The augmented specification without controls for children and earnings is used, since both variables may be endogenous to marital status, whereas age, quarter of birth, education and being Hispanic are not.
} 
cohabiting, and finally on being never married cohabiting versus never married single, to further investigate the nature of these season of birth effects on marital outcomes by gender and race.

[Table 3 about here]

The corresponding seasonal estimates are consistent with Table 2 but provide more nuanced patterns and refined differences between types of relationship. As before, one can see that for white women it is the fourth quarter of birth to play a role, although being youngest in the cohort improves marital outcomes only in terms of being legally married rather than cohabiting, i.e., it affects the type of relationship, not the odds of being or not in a relationship. The exponential of the point estimate associated to the fourth quarter (.056) shows that the odds of being married rather than cohabiting are 1.06 times significantly higher than the odds if born in another quarter. While black women do not exhibit any seasonal pattern in this decomposition either, the evidence on disaggregated patterns for men now highlights quarter of birth effects. For white men, there is only a mildly significant but sizable association between second quarter of birth and being less likely to be cohabiting rather than single (odds ratio $=.96$ ), whereas for black men the first quarter of birth is associated to a significant decrease in the likelihood of being cohabiting rather than single (odds ratio about .91), as well as to an increase in the odds of being married rather than cohabiting (odds ratio $=1.08$ ), with only the fourth birth quarter positively affecting the chances of being married rather than single.

This evidence seems to suggest that the fourth quarter of birth may contribute to female attractiveness in the marriage market, while early quarters of birth, the first quarter of birth in particular, may enhance male attractiveness, and the estimated gender difference in this season of birth effect would be consistent with the observation that being relatively younger is not perceived as attractive in a men. 
It seems that selection into marriage versus cohabitation, or the odds to remain in such a relationship, are different for white women born in the fourth quarter, with these later born women more likely to be married, but at the same time not more likely to be in a cohabiting union than by themselves. For black men instead, it is the first birth quarter that increases the odds of marriage versus cohabitation, while also decreasing those of being in a relationship at all. If marriage in the US is considered superior to cohabitation, ${ }^{3}$ then these patterns are consistent with a selection into marriage for white women and black men, but interestingly not for black women, whose selectivity is impaired by group size in that they suffer from a severe marriage market imbalance and cannot "afford" to be selective when choosing a mate or a relationship type, with "better quality" black men either committing to marriage or enjoying singlehood (Banks, 2011; Loughran, 2002).

Family dissolution. The empirical analysis now extends to divorce patterns. Table 4 presents binomial logistic regressions of dummy variables of being divorced rather than married, of being divorced rather than never married, or of being ever divorced (currently divorced or being remarried which implies having divorced) rather than married or never married, on quarter of birth indicators, age, education, and being Hispanic, estimated separately by gender and race. This evidence presents significant associations only for women, and interestingly enough these involve birth quarters different from those playing a role in family formation. Specifically, being born in the third quarter makes it significantly more likely to be divorced than married or never married, or to be ever divorced for white women, whereas for black women it is the second birth quarter, with a significant odds ratio of 1.05 and 1.02 , respectively. ${ }^{4}$

[Table 4 about here]

\footnotetext{
${ }^{3}$ See, for instance, Becker (1991), Browning, Chiappori, Weiss (2014), Lundberg and Pollak (2013).

${ }^{4}$ These findings are robust to including separated in the same category as the divorced.
} 
It is remarkable that different quarters of birth are involved in the formation and dissolution of couples, which may indicate that season of birth is indeed a trait capturing some relevant aspect of an individual's attractiveness and household behavior.

\subsection{Matching patterns in couples}

The above evidence is the first to establish that season of birth affects marital outcomes in terms of marriage, cohabitation, singlehood, and divorce. However, in the marriage market and in terms of individual and household wellbeing, not only whether one is matched or not is important, but also with whom this match is formed. That is, not only whether one has a spouse (partner) or not matters in order to determine the sorting patterns, but also which type of person (with which characteristics) one can match with given his/her own attributes (Browning, Chiappori and Weiss, 2014).

In this spirit, the following analysis addresses a different question, namely "who marries whom", by studying the matching patterns and spousal (partner's) trade-offs among quarters of birth on one side and socioeconomic characteristics (education and earnings) on the other, among married and cohabiting couples, where cohabitation is incorporated as a separate relationship. Specifically, I run regressions for both husbands and wives, of own education, or earnings, on own quarters of birth, age, Hispanic dummy, and on the spouse's quarters of birth and education (or earnings), to estimate whether and how season of birth correlates with socioeconomic factors while accounting for the well-known sorting by socioeconomic status that exists in the marriage market. This is to determine whether, to what extent, and which quarters of birth have any impact on sorting by spousal/partner's attributes, conditional on having formed a match and in addition to the season of birth effects documented above on the formation and dissolution of 
relationships. Any significant spousal/partner's trade-offs with season of birth should be less likely to emerge, given the above evidence on season of birth already affecting the probability of forming a match.

Table 5 presents the regressions of education on own characteristics and the spouse's quarter of birth and education, for white married couples. It shows that women born in the first quarter have less educated husbands than other wives do (column 2). For men, there is only a mildly significant positive relationship between first quarter of birth and their wives' education (column 2). As to the trade-offs between earnings and quarters of birth, there is a positive significant correlation between the husband's first quarter of birth and the log of the wife's earnings (column 3), showing that relatively older men marry richer wives, ceteris paribus, and the point estimate corresponds to about two percentage points.

[Table 5 about here]

Table 6 shows the same regressions for black married couples, who do not exhibit any spousal trade-off with education and birth quarters (column 1), whereas one can see a strong positive correlation between the female fourth quarter of birth and their husbands' earnings or log earnings, corresponding to a seven percentage point increase in earnings with respect to the husbands of women born in other quarters (columns 3 and 5). There is also a mildly significant association of the male fourth quarter of birth and wives' earnings that is robust to dropping observations with zero earnings (specification with the logarithm of earnings, column 5).

[Table 6 about here]

The disparity by gender in the estimated spousal socioeconomic trade-offs among birth quarters and socioeconomic characteristics provides additional support to the interpretation that season of birth may influence individual attractiveness in the marriage market, and that potential spouses 
penalize or reward different quarters of birth according to gender. The strongly significant tradeoffs may seem to suggest that female relative youth (younger perceived age) is positively assessed in the marriage market, in that those women born in the fourth quarter match with better husbands or that those from the first one match with worse ones, ceteris paribus, while relatively older and mature men from the first quarter get better wives.

Table 7 reports the evidence on cohabiting couples. As to education, there is only a mildly significant negative trade-off for white men between the third quarter of birth and their partner's education, while more significant correlations are found on earnings. In white couples there is a mildly significant positive trade-off between the male third quarter of birth and their partner's log of earnings, corresponding to a five percentage point increase, while in black couples a positive correlation between the female fourth quarter of birth and their partner's earnings is estimated. For log of earnings this positive correlation is observed for all the quarters with respect to the first one, and also for the male third quarter of birth on female log earnings.

\section{[Table 7 about here]}

The significant trade-offs across spousal (partner's) attributes and the fact that season of birth significantly shapes sorting patterns is all the more remarkable given its already strong influence on family formation and dissolution documented above, and the variety of controls (age, education, and own quarters of birth) and specifications considered in this analysis.

As to the other covariates in the spousal (partner's) trade-offs equations of Tables 5-8, it is reassuring to find the well-known strong positive sorting by education among both married and cohabiting couples (estimated correlation of about .60 in line with the literature, e.g., Qian, 1998) along with the expected associations of own age and ethnicity with education and earnings. It is also interesting to note that the sorting by earnings varies by race and marital status. In married 
couples, it is always positive for blacks, while for whites it is estimated to be positive when nonpositive earners are excluded, and negative when they are not, whereas in cohabiting couples the sorting by earnings is always positive. This is consistent with the main matching patterns by race and the corresponding differences in female labor force participation decisions between white and black married women, and between married and cohabiting women. Finally, the significant coefficients on spousal (partner's) quarters of birth bear the same sign as those of own quarters of birth

Married couples differ from cohabiting ones in that the former exhibit more significant spousal trade-offs that clearly highlight the positive role of the male earlier birth quarters and the female later ones in attracting a better spouse. In cohabiting couples, the female fourth quarter still plays a positive role but only for black women, while for men it is the third quarter that matters. This difference between marriage and cohabitation among whites is consistent with the weaker social status of the latter, and the different selection into type of relationship according to the fourth

\footnotetext{
${ }^{5}$ Results are also robust to exclude the self-employed, or to focusing on recently-married couples, although this latter restriction is not crucial here since season of birth is predetermined with respect to marital outcomes. I have also explored two measures of early marriage, having married by age 21 for those who are now 25 years old, or age at marriage, and the probability to be the head of the household, conditional on being in a couple. The fourth birth quarter seems to be associated with marrying later for white women, for black women, instead, the second and third quarters of birth seem to make early marriage more likely. The third quarter seems to increase the probability of being household head for white women, while black women born in the first quarter of the year are more likely to be heading their household. These weak associations do not contradict the main patterns of results, as in female marriage patterns it is not true that women from the first birth quarter marry earlier because they finish school earlier, highlighting once again that season of birth affects marital outcomes directly rather than through the socioeconomic channel.
} 
quarter of birth found in the above analysis on individual marital outcomes. Furthermore, the fact that for black women later quarters of birth are relevant also for cohabiting unions may reflect the role of the fourth birth quarter in selecting women into cohabitation (Table 3) and the aspect that blacks may consider cohabitation equal to marriage since black women are in strong excess supply and have to compete in this cohabitation market as well.

These findings represent the first evidence on season of birth directly affecting marital outcomes and who is matched with whom, as season of birth is predetermined and invariant with respect to marital outcomes. Also, the documented patterns cannot be driven by an imbalance in the population of men and women across birth quarters, given that the distribution of quarters of birth is symmetric across genders (Table 1), also within education brackets, so that there is no group in the marriage market who is in excess or short supply by season of birth.

Both the effect on marriage probability and the one on type of spouse/partner are consistent with the observation that male attractiveness depends more on maturity and self-confidence than on youth or physical attributes, the opposite being true for women (Case and Paxson, 2008; Grossbard-Schechtman, 1993; Hitsch, Hortaçsu, Ariely, 2010; Oreffice and Quintana-Domeque, 2010; Townsend and Wasserman, 1998). Indeed, men from earlier quarters are taller, physically stronger, more confident, and exhibit more reproductive success than men born in other quarters, while women from the fourth quarter are relatively younger and perceived age may be a better indication of biological fitness than chronological age (Huber et all., 2004; Townsend and Wasserman, 1998; Weber, Prossinger, Sendler, 1998). This "evolutionary" interpretation would also match the evidence from psychological studies on family relationships and the differences between marriage and cohabitation discussed above. 


\section{Season of birth in marital outcomes: alternative explanations}

Overall, the findings consistently show the effects of season of birth (especially the first and fourth birth quarters for men and women, respectively) on a variety of marital outcomes, and that the estimated impact of season of birth on later outcomes is wider than previously thought as it extends to marital outcomes. Moreover, this influence is not capturing an indirect effect of socioeconomic status on the marriage market, since the empirical analysis accounts for education and/or earnings, and the quarter of birth traditionally associated to lower socioeconomic status and lower high-school graduation rates in the US is the first one regardless of gender (Angrist and Krueger, 1991, Buckles and Hungerman, 2013), differently from the estimated impact on marital outcomes.

Recent work in economics has investigated the mechanism of how quarter of birth ultimately affects socioeconomic status. Buckles and Hungerman (2013) contend that maternal characteristics affect seasonality of birth, with mothers of lower socioeconomic status more likely to have first quarter births, whereas Currie and Schmadt (2013) use mother's fixed effects and show that the channel leading to the lower socioeconomic status of individuals born in the first quarter is the disease prevalence in winter, and its associated impact on birth weight and gestational weeks. While acknowledging these strong associations with socioeconomic status, this paper argues that the above studies cannot provide an alternative explanation for its findings on marital outcomes since it controls for socioeconomic factors both in terms of education and earnings, season of birth is predetermined and invariant to marriage, the sample under analysis has completed its education, and a systematic analysis of season of birth and marital outcomes was missing in the literature. Finally, these findings reinforce the warning of caution by Buckles 
and Hungerman (2013) in using season of birth as an instrument, actually extending the caution to other types of outcomes to which it appears to be endogenous, namely marriage.

Works in the medical literature have emerged on the links between season of birth and physical and psychiatric outcomes, with different quarters of birth affecting different types of traits, although the mechanisms behind these associations are still largely unknown. These phenomena cannot consistently explain the results of this study, given that these other later outcomes associated to season of birth are not significantly related to the same quarters of birth as those affecting marital outcomes and they do not exhibit the same patterns by gender and race that instead the above evidence shows. In fact, many works on physical or psychiatric effects of season of birth specifically focus on only one gender and one race (e.g., Weber, Prossinger, Seiger, 1998).

Specifically, the above findings on marital outcomes cannot simply capture the associations of quarters of birth with height, physical performance, health, or personality traits that have been established in the literature (e.g., Disanto et al., 2011; McGrath et el., 2006; Tonetti, Fabbri, Natale, 2009; Weber, Prossinger, Seiger, 1998). Men are found to be taller if born in the Spring, shorter if born in the Fall, and less conscientious if from the third birth quarter, although the impact of seasonality extends well beyond personality. In addition, physical performance in sports is positively related to births early in the year, while Winter and early Spring births are more likely to later develop schizophrenia, showing better physical and cognitive outcomes till age 7 (McGrath et el., 2006). Finally, the scant evidence on season of birth and obesity suggests that the prevalence of the latter is higher for those men born in the first semester of the year, but no significant association emerges for women (Phillips and Young, 2000). As BMI affects physical attractiveness which in turn matters in the marriage market, men born in the first 
semester may appear less attractive, if heavier. However, this cannot represent an alternative explanation to my findings on the fourth quarter of birth enhancing female marital outcomes and the first quarter of birth, if anything, enhancing male ones.

\section{Conclusions}

A renewed interest in how and to what degree season of birth affects individuals' socioeconomic, physical and psychiatric traits has recently emerged, although it faces the challenge to document and understand exactly which later outcomes are affected by season of birth and why.

This is the first study to state and offer empirical support to the hypothesis that season of birth directly affects marriage market outcomes beside socioeconomic status, acknowledging that family formation, dissolution and marital sorting are important demographic outcomes in an individual's life that have not yet been considered in this growing literature on season of birth. This analysis is strengthened by the fact that season of birth is a trait that is clearly time-invariant and pre-determined with respect to marital status and socioeconomic status, which is not necessarily the case for other non-socioeconomic characteristics playing a role in the marriage market.

The goal of this paper has been to investigate whether quarter of birth has any impact on marital outcomes that is not channeled through socioeconomic status, controlling for the well-known influence that the latter has on the marriage market, both in terms of education and earnings. The empirical analysis is the first work to explore whether the marriage market may reward or penalize individuals from specific quarters of birth by affecting their marriage and divorce probabilities, and by matching them with more or less socially desirable spouses or partners, estimating these patterns separately by gender and race. The comparisons by types of couples 
and individuals have helped to better understand the general role of season of birth and to suggest an interpretation in terms of attractiveness by gender, relative youth or maturity.

US Population Census data are used, specifically the American Community Survey for the years 2010, 2011, and 2012, which represent one-percent national random samples of the population and provide the most recent and the largest sample of detailed demographic and socioeconomic information on individuals in the US. In particular, these data provide quarter of birth information for each individual and his/her marital status, but they also allow identification of spouses and unmarried partners so that the latter can be distinguished from single individuals not in a relationship.

White women born in the fourth quarter are shown to be more likely to be married than never married, and this significant difference is driven by the fourth quarter influencing the type of relationship (married more likely than cohabiting) rather than the odds of being married instead of single. Conversely, never married white men from the second birth quarter are less likely to be cohabiting than single, showing that for white men season of birth is related to being or not in a relationship rather than to the type of relationship. Black men from the first quarter are less likely to be married rather than cohabiting but more likely to be cohabiting than single, so that for black men high season of birth decreases the odds of being married. No such patterns are found for black women. In terms of family dissolution, white women from the third birth quarter and black women from the second are more likely to be divorced.

As to matching patterns, in white married couples men born in the first quarter have more educated and richer wives than other men do, and women from the first quarter have less educated husbands than other women do. Among cohabiting couples, white men and women born in the third quarter have richer and less educated partners, respectively, and black women 
from the first quarter have poorer partners. Finally, in all types of couples black women born in the fourth quarter have richer husbands than other women do.

The main contribution of this paper is to add the relevant life aspects of family formation, dissolution, and spousal (partner's) trade-offs with socioeconomic characteristics into the spectrum of documented effects of season of birth, by showing that higher quarters of birth affect male marital outcomes and lower quarter of births affect female ones, with interesting differences by race and relationship type. 


\section{References}

1. Angrist, J.D., Krueger, A.B. (1991), "Does compulsory school attendance affect schooling and earnings?", Quarterly Journal of Economics, 106-4, 979-1014.

2. Averett, S.L., Sikora, Argys, L.M. (2008), "For better or worse: relationship status and body mass index", Economics and Human Biology, 6-3, 330-349.

3. Banks, R. (2011), “Is Marriage for White People?”, Dutton Press.

4. Becker, G. (1991), “A Treatise on the Family”, Harvard University Press.

5. Bound, J., Jaeger, D.A. (1996), "On the Validity of Season of Birth as an Instrument in Wage Equations: A Comment on Angrist \& Krueger's "Does compulsory school attendance affect schooling and earnings?'”, NBER Working Paper Series, \# 5835.

6. Browning, M., Chiappori, P., Weiss, Y. (2014), "Family Economics", Cambridge University Press.

7. Buckles, K.S., Hungerman, D.M. (2013), "Season of Birth and Later Outcomes: Old Questions, New Answers", Review of Economics and Statistics, 95-3, 711-724.

8. Case, A., Paxson, C. (2008), "Stature and Status: Height, Ability, and Labor Market Outcomes", Journal of Political Economy, 116-3, 499-532.

9. Chiappori, P., Oreffice, S., Quintana-Domeque, C. (2012), "Fatter Attraction: Anthropometric and Socioeconomic Matching on the Marriage Market", Journal of Political Economy, 120-4, 659-695.

10. Currie, J., Schwandt, H. (2013), "Within-mother analysis of seasonal patterns in health at birth”, Proceedings of the National Academy of Sciences, 110-30, 12265-12270.

11. Disanto, G., Handel, A., Para, A., Ramagopalan, S., Handunnetthi, L. (2011), "Season of birth and anorexia nervosa", The British Journal of Psychiatry, 198, 404-405. 
12. Dupuy, A., Galichon, A. (2014), "Personality traits and the marriage market", Journal of Political Economy, forthcoming.

13. Grossbard-Shechtman, S. (1993), "On the economics of marriage. A theory of marriage, labor and divorce", Westview Press.

14. Hitsch, G.J., Hortaçsu, A., Ariely, D. (2010), "Matching and Sorting in Online Dating", American Economic Review, 100-1, 130-163.

15. Huber, S., Fieder, M., Wallner, B., Iber, K., Moser, G. (2004), “Effects of season of birth on reproduction in contemporary humans: brief communication", Human Reproduction, $19-2,445-447$.

16. Loughran, D.S. (2002), "The effect of male wage inequality on female age at first marriage", Review of Economics and Statistics, 84-2, 237-250.

17. Lundberg, S., Pollak, R.A. (2013), "Cohabitation and the Uneven Retreat from Marriage in the U.S., 1950-2010”, NBER Working Paper Series, \# 19413.

18. Lundberg, S. (2012), "Personality and marital surplus", IZA Journal of Labor Economics, $1-3$.

19. Malcolm, M., Kaya, I. (2014), "Selection works both ways: BMI and marital formation among young women", Review of Economics of the Household, forthcoming.

20. McGrath, J., Saha, S., Lieberman, D., Buka, S. (2006), "Season of birth is associated with anthropometric and neurocognitive outcomes during infancy and childhood in a general population birth cohort", Schizophrenia Research, 81-1, 91-100.

21. Neal, D. (2004), "The Relationship between Marriage Market Prospects and NeverMarried Motherhood", Journal of Human Resources, 39-4, 938-957. 
22. Oreffice, S., Quintana-Domeque, C. (2010), “Anthropometry and socioeconomics among couples: evidence in the United States", Economics and Human Biology, 8-3, 373-384.

23. Phillips, D.I.W., Young, J.B. (2000), "Birth weight, climate at birth and the risk of obesity in adult life", International Journal of Obesity, 24-3, 281-287.

24. Qian, Z. (1998), "Changes in assortative mating: the impact of age and education, 19701990", Demography, 35-3, 279-292.

25. Ruggles, S., Alexander, T., Genadek, K., Goeken, R., Schroeder, M.B., Sobek, M. (2010), "Integrated Public Use Microdata Series: Version 5.0 [Machine-readable database]", University of Minnesota.

26. Spivey, C. (2010), "Desperation or desire? The role of risk aversion in marriage", Economic Inquiry, 48-2, 499-516.

27. Tonetti, L., Fabbri, M., Natale, V. (2009), "Season of birth and personality in healthy young adults", Neuroscience Letters, 452-2, 185-188.

28. Townsend, J.M., Wasserman, T. (1998), "Sexual attractiveness: Sex differences in assessment and criteria", Evolution and Human Behavior, 19-3, 171-191.

29. Weber, G.W., Prossinger, H., Seidler, H. (1998), "Height depends on month of birth", Nature, 391, 754-755.

30. Wilson, W. J. (1987), “The Truly Disadvantaged. The Inner City, The Underclass, and Public Policy", University of Chicago Press. 
Table 1a: Descriptive statistics. White sample.

\begin{tabular}{|c|c|c|c|c|c|c|c|c|c|c|c|c|}
\hline & \multicolumn{4}{|c|}{ Individuals } & \multicolumn{4}{|c|}{ Married Sample } & \multicolumn{4}{|c|}{ Cohabiting Sample } \\
\hline & \multicolumn{2}{|c|}{ Women } & \multicolumn{2}{|c|}{ Men } & \multicolumn{2}{|c|}{ Women } & \multicolumn{2}{|c|}{ Men } & \multicolumn{2}{|c|}{ Women } & \multicolumn{2}{|c|}{ Men } \\
\hline & Mean & Std. Dev. & Mean & Std. Dev. & Mean & Std. Dev. & Mean & Std. Dev. & Mean & Std. Dev. & Mean & Std. Dev. \\
\hline $1^{\text {st }}$ quarter of birth & .24 & .43 & .24 & .43 & .24 & .43 & .24 & .43 & .25 & .43 & .24 & .43 \\
\hline $2^{\text {nd }}$ quarter of birth & .24 & .43 & .25 & .43 & .25 & .43 & .25 & .43 & .25 & .43 & .25 & .43 \\
\hline $3^{\text {nd }}$ quarter of birth & .26 & .44 & .26 & .44 & .26 & .44 & .26 & .44 & .26 & .44 & .27 & .44 \\
\hline $4^{\text {rth }}$ quarter of birth & .25 & .43 & .25 & .43 & .25 & .43 & .25 & .43 & .24 & .43 & .25 & .43 \\
\hline Age & 35.50 & 5.98 & 35.72 & 5.90 & 34.22 & 5.27 & 35.78 & 5.33 & 28.99 & 4.57 & 31.06 & 4.82 \\
\hline Education & 14.20 & 2.11 & 13.87 & 2.12 & 14.48 & 2.05 & 14.15 & 2.12 & 13.91 & 2.11 & 13.41 & 2.08 \\
\hline Hispanic & .08 & .27 & .07 & .26 & .06 & .24 & .06 & .23 & .10 & .29 & .10 & .30 \\
\hline N. of young children & .37 & .65 & .36 & .65 & .59 & .75 & .59 & .75 & .16 & .44 & .15 & .43 \\
\hline Earnings & 32,268 & 32,857 & 56,138 & 50,356 & 30,333 & 33,092 & 66,038 & 56,505 & 28,802 & 26,014 & 40,765 & 35,145 \\
\hline Married & .76 & .43 & .70 & .46 & & & & & & & & \\
\hline Cohabiting & .11 & .31 & .13 & .33 & & & & & & & & \\
\hline Divorced & .13 & .34 & .10 & .30 & & & & & & & & \\
\hline Household head & .39 & .49 & .58 & .49 & & & & & & & & \\
\hline N. of observations & 427,822 & & 463,135 & & 203,130 & & 203,130 & & 18,613 & & 18,613 & \\
\hline
\end{tabular}

Note. US Census American Community Survey data 2010-2012. 
Table 1b: Descriptive statistics. Black sample.

\begin{tabular}{|c|c|c|c|c|c|c|c|c|c|c|c|c|}
\hline & \multicolumn{4}{|c|}{ Individuals } & \multicolumn{4}{|c|}{ Married Sample } & \multicolumn{4}{|c|}{ Cohabiting Sample } \\
\hline & \multicolumn{2}{|c|}{ Women } & \multicolumn{2}{|c|}{ Men } & \multicolumn{2}{|c|}{ Women } & \multicolumn{2}{|c|}{ Men } & \multicolumn{2}{|c|}{ Women } & \multicolumn{2}{|c|}{ Men } \\
\hline & Mean & Std. Dev. & Mean & Std. Dev. & Mean & Std. Dev. & Mean & Std. Dev. & Mean & Std. Dev. & Mean & Std. Dev. \\
\hline $1^{\text {st }}$ quarter of birth & .25 & .43 & .25 & .43 & .24 & .43 & .26 & .44 & .25 & .43 & .23 & .42 \\
\hline $2^{\text {nd }}$ quarter of birth & .23 & .42 & .23 & .42 & .22 & .42 & .23 & .42 & .24 & .43 & .23 & .42 \\
\hline $3^{\text {nd }}$ quarter of birth & .27 & .44 & .27 & .44 & .28 & .45 & .26 & .44 & .28 & .45 & .28 & .45 \\
\hline $4^{\text {rth }}$ quarter of birth & .26 & .44 & .26 & .44 & .25 & .43 & .26 & .44 & .23 & .42 & .26 & .44 \\
\hline Age & 35.56 & 5.92 & 35.90 & 5.89 & 35.00 & 5.11 & 34.49 & 5.28 & 30.83 & 5.16 & 32.92 & 5.33 \\
\hline Education & 13.35 & 1.97 & 13.15 & 1.84 & 13.90 & 1.99 & 13.36 & 1.89 & 13.06 & 1.83 & 12.54 & 1.52 \\
\hline Hispanic & .02 & .14 & .02 & .13 & .02 & .13 & .01 & .11 & .02 & .15 & .018 & .13 \\
\hline N. of young children & .29 & .58 & .24 & .55 & .45 & .68 & .45 & .68 & .29 & .60 & .20 & .49 \\
\hline Earnings & 27,480 & 26,491 & 36,954 & 33,171 & 31,651 & 30,017 & 43,805 & 37,506 & 23,244 & 21,393 & 27,010 & 24,220 \\
\hline Cohabiting & .09 & .29 & .18 & .39 & & & & & & & & \\
\hline Divorced & .13 & .33 & .11 & .31 & & & & & & & & \\
\hline Household head & .48 & .50 & .45 & .50 & & & & & & & & \\
\hline N. of observations & 57,733 & & 36,835 & & 9,392 & & 9,392 & & 2,264 & & 2,264 & \\
\hline
\end{tabular}




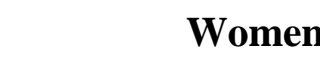

(1)

$(2)$

(3)

A. White

$2^{\text {nd }}$ quarter of birth

$(.014)$

.015

(.014)

.018

(.015)

$3^{\text {rd }}$ quarter of birth

$4^{\text {th }}$ quarter of birth

Age

Education

Hispanic

Young children

Earnings

$\mathrm{N}$

Pseudo $\mathrm{R}^{2}$

\section{B. Black}

\section{.010}

(.034)

$.055^{*}$

(.033)

.014

(.035)

.014

(.036)

.053

(.034)

.047

(.034)

$4^{\text {th }}$ quarter of birth

Age

Education

Hispanic

Young children

Earnings

$\mathrm{N}$

Pseudo R ${ }^{2}$

$$
-.017
$$$$
\text { (.033) }
$$$$
-.017
$$$$
\text { (.034) }
$$$$
-.023
$$$$
\text { (.035) }
$$

$.080^{* * *}$

$$
.080^{* * * *}
$$

(.002)

$.102^{* * * *}$

(.002)

$.197^{* * *}$

$.178^{* * *}$

(.006)

(.007)

$.410^{* * * *}$

$.422^{* * * *}$

(.083)

(.084)

$.642^{* * * *}$

(.022)

$.000004^{* * *}$

(.000)

$50,297 \quad 50,297 \quad 50,297$

.096

Men

(4)

(5)

(6)

$\begin{array}{ccc}-.004 & -.006 & -.005 \\ (.014) & (.014) & (.015) \\ -.010 & -.009 & -.003 \\ (.014) & (.014) & (.015) \\ -.004 & -.004 & -.007 \\ (.014) & (.014) & (.015) \\ .109^{* * *} & .108^{* * *} & .125^{* * *} \\ (.001) & (.001) & (.001) \\ & .067^{* * *} & -.020^{* * *} \\ & (.002) & (.003) \\ & -.027 & -.032 \\ & (.020) & (.023) \\ & & 2.31^{* * *} \\ & & (.022)\end{array}$

$1.3 \cdot 10^{-5 * * *}$ $\left(2 \cdot 10^{-7}\right)$

$388,576 \quad 388,576 \quad 388,576$

$.072 \quad .075$

.242

$\begin{array}{ccc}-.017 & -.028 & -.009 \\ (.041) & (.041) & (.044) \\ -.043 & -.051 & -.018 \\ (.039) & (.039) & (.042) \\ .048 & .040 & .048 \\ (.040) & (.040) & (.043) \\ .085^{* * *} & .086^{* * *} & .111^{* * *} \\ (.002) & (.002) & (.003) \\ & .125^{* * *} & .026^{* * *} \\ & (.008) & (.009) \\ & .230^{* *} & .195^{* * *} \\ & (.096) & (.107) \\ & & 1.72^{* * *} \\ & & (.047) \\ & & .00001^{* * *} \\ & & (.000) \\ 33,034 & 33,034 & 33,034 \\ .053 & .062 & .176\end{array}$

Note. Omitted category is the first quarter of birth. Regressions include state and year fixed effects. Observations have been weighted by using person weights. Heteroskedasticity robust standard errors are reported in parentheses. $* * *$ p-value $<0.01$, ** p-value $<0.05, *$ p-value $<0.1$ 
Table 3: Logit estimates of being in a relationship on quarter of birth indicators and other individual characteristics.

\begin{tabular}{|c|c|c|c|c|c|}
\hline \multicolumn{3}{|c|}{ Women } & \multicolumn{3}{|c|}{ Men } \\
\hline Married & Married & Cohabiting & Married & Married & Cohabiting \\
\hline $\begin{array}{c}\text { vs } \\
\text { Single }\end{array}$ & $\begin{array}{c}\text { vs } \\
\text { Cohahiting }\end{array}$ & $\begin{array}{c}\text { vs } \\
\text { Single }\end{array}$ & $\begin{array}{c}\text { vs } \\
\text { Single }\end{array}$ & vs & $\begin{array}{c}\text { vs } \\
\text { Sincle }\end{array}$ \\
\hline
\end{tabular}

(1) (2) (3)

\section{A. White}

$2^{\text {nd }}$ quarter of birth

$$
.007
$$

(.017)

.033

(.023)

$-.027$

(.026)

(4)

(5)

(6)

$3^{\text {rd }}$ quarter of birth

.021

(.016)

.019

(.022)

$-.007$

(.026)

$4^{\text {th }}$ quarter of birth

.025

(.017)

$.056^{* *}$

(.023)

$-.036$

(.026)

Age

$.084^{* * *}$

(.001)

$.150^{* * * *}$

$-.059^{* * *}$

(.002)

(.002)

Education

$-.002$

(.003)

$.107^{* * *}$

(.004)

$-.116^{* * *}$

(.004)

Hispanic

$-.323^{* * *}$

$-.124^{* * * *}$

$-.231^{* * * *}$

(.034)

$-.020$

(.016)

.021

(.021)

$-.045^{*}$

$-.006$

$-.021$

(.024)

(.016)

(.021)

.010

$-.012$

.019

(.021)

(.024)

(.016)

$.142^{* * *}$

$.094^{* * *}$

(.001)

$-.023$

(.024)

(.001)

$-.044^{* * *}$

$.013^{* * *}$

$.159^{* * *}$

(.001)

(.003)

(.004)

$-.176^{* * * *}$

(.004)

$.057^{* *}$

$-.147^{* * *}$

$.217^{* * *}$

(.024)

N

377,662

350,887

86,927

351,675

(.029)

102,327

Pseudo R ${ }^{2}$

.046

.110

.032

.053

323,150

.037

\section{B. Black}

$2^{\text {nd }}$ quarter of birth

$$
\begin{gathered}
.016 \\
(.036)
\end{gathered}
$$

$-.012$

(.037)

.008

(.032)

.016

$-.075^{* *}$

$.094^{* *}$

$3^{\text {rd }}$ quarter of birth

.050

(.034)

.033

(.035)

$-.005$

(.031)

(.046)

(.034)

(.037)

$4^{\text {th }}$ quarter of birth

$-.011$

$-.044$

(.035)

.010

(.031)

.002

$-.101^{* * * *}$

$.094^{* * * *}$

(.044)

(.033)

(.036)

(.035)

$.068^{* * * *}$

$-.023^{* * *}$

$.113^{* * *}$

$-.063^{*}$

$.137^{* * * *}$

(.045)

(.033)

(.036)

Age

$.074^{* * * *}$
$(.002)$

(.002)

(.002)

$.072^{* * *}$

$.067^{* * *}$

(.002)

$-.025^{\text {*** }}$

(.003)

(.002)

Education

$.192^{* * *}$
$(.006)$

$.128^{* * * *}$

$-.008$

$.067^{* * * *}$

$.148^{* * * *}$

$-.112^{* * *}$

(.006)

(.009)

(.007)

(.007)

Hispanic

$.491^{\text {*** }}$

.041

$.279^{\text {*** }}$

$.326^{* * *}$

.038

$.170^{* *}$

(.113)

(.075)

(.085)

N

45,979

22,922

31,679

27,484

23,112

15,457

.070

.110

.014

.046

.108

.036

Note. Omitted category is the first quarter of birth. Regressions include state and year fixed effects. Observations have been weighted by using person weights.

Heteroskedasticity robust standard errors are reported in parentheses. *** $\mathrm{p}$-value $<0.01, * * \mathrm{p}$-value $<0.05, * \mathrm{p}$-value $<0.1$. 
Table 4: Logit estimates of being divorced versus married, or divorced versus never married, or of having ever divorced on quarter of birth indicators and other individual characteristics.

\begin{tabular}{ccc} 
& Women \\
\hline Divorced & Divorced & Ever \\
vs & vs & Divorced \\
Married & Never Married & Div
\end{tabular}

(1)

(2)

(3)

\section{A. White}

\section{$2^{\text {nd }}$ quarter of birth}

$3^{\text {rd }}$ quarter of birth

$4^{\text {th }}$ quarter of birth

$.025 \quad .035$

$(.020)$

(.027)

$.039^{* *}$

(.020)

$.057^{* *}$

(.027)

.004

(.020)

.022

(.027)

$.083^{* * *}$

(.001)

$-.168^{* * *}$
$(.003)$

.

(.028)

360,108

.055

$$
.157^{* * *}
$$

(.002)

$-.167^{* * *}$

(.005)

$-.213^{* * *}$

(.035)

96,148

.179
.096
Age

Education

Hispanic

$\mathrm{N}$

Pseudo $\mathrm{R}^{2}$

\begin{abstract}
$.018^{* *}$
\end{abstract}
(.007)

(.010)

.007

$-.005$

(.010)

(.007)

$4^{\text {th }}$ quarter of birth

Age

.002

(.010)

.007

(.007)

$.015^{* * * *}$

(.0006)

$.020^{* * * *}$

(.0004)

Education

$-.021^{* * *}$

$.012^{* * *}$

(.001)

.0002

(.022)

$.071^{* * * *}$

(.021)

25,161

33,943

.041

.122

\begin{tabular}{ccc}
\multicolumn{3}{c}{ Men } \\
\hline Divorced & Divorced & Ever \\
vs & vs & Divorced
\end{tabular}

(4)

(5)

(6)

\begin{tabular}{ccc}
\hline & & \\
-.002 & -.025 & -.018 \\
$(.025)$ & $(.030)$ & $(.014)$ \\
-.006 & .013 & -.013 \\
$(.024)$ & $(.030)$ & $(.014)$ \\
.027 & .010 & .006 \\
$(.025)$ & $(.030)$ & $(.014)$ \\
$.085^{* * *}$ & $.155^{* * *}$ & $.118^{* * *}$ \\
$(.002)$ & $(.002)$ & $(.001)$ \\
$-.169^{* * *}$ & $-.126^{* * *}$ & $-.195^{* * *}$ \\
$(.004)$ & $(.005)$ & $(.002)$ \\
$-.176^{* *}$ & $-.090^{* * *}$ & $-.190^{* * *}$ \\
$(.040)$ & $(.045)$ & $(.023)$ \\
311,881 & 91,058 & 480,239 \\
.051 & .162 & .100
\end{tabular}
$.014^{* * *}$
(.006)

.003

(.005)

.005

(.005)

$.018^{* * * *}$

(.0003)

$$
\begin{gathered}
.009 \\
(.009)
\end{gathered}
$$

.016

(.012)

.077

(.048)

$-.001$

$-.002$

(.012)

.019

(.047)

$\begin{array}{ll}.001 & .014\end{array}$

.032

(.009)

(.012)

(.047)

$.011^{* * *}$

$.023^{* * * *}$

$.130^{* * * *}$

(.0006)

(.001)

(.003)

$-.0003$

(.0009)

$-.007^{* * * *}$

$.007^{* * * *}$

(.002)

$-.040^{* * * *}$

(.009)

$.054^{* * *}$

(.002)

.050

.180

(.023)

(.038)

(.118)

61,756

20,107

12,472

40,543

.046

.131

.085

Note. Omitted category is the first quarter of birth. Regressions include state and year fixed effects. Observations have been weighted by using person weights. Heteroskedasticity robust standard errors are reported in parentheses. *** p-value $<0.01, * *$ p-value $<0.05, *$ p-value $<0.1$. 
Table 5: White married couples. Regressions of socioeconomic factors on own characteristics and spouse's quarter of birth indicators and socioeconomic factor.

$\frac{\text { Education }}{\text { Wives Husbands }}$

(1)
(2)

Age

$\begin{array}{ll}.003^{* * *} & .018^{* * *} \\ (.009) & (.001)\end{array}$

Hispanic

$-.426^{* * *}$

$-.425^{* * *}$

(.023)

(.023)

$2^{\text {nd }}$ quarter of birth

.014

(.013)

$-.025^{*}$

$-.009$

(.014)

$3^{\text {rd }}$ quarter of birth

(.013)

$-.005$

(.013)

$4^{\text {th }}$ quarter of birth

.0001

(.013)

$$
-.003
$$

(.014)

$2^{\text {nd }}$ quarter of birth spouse

$-.023^{*}$

(.013)

$.038^{* * * *}$

(.014)

$3^{\text {rd }}$ quarter of birth spouse

$-.022^{*}$

(.013)

$.023^{*}$

(.013)

$4^{\text {th }}$ quarter of birth spouse

$-.016$

(.013)

$.024^{*}$

(.014)

Education spouse

$.560^{* * * *}$

$.602^{* * * *}$

(.003)

Earnings spouse

Log of Earnings spouse

$$
\begin{aligned}
& \text { N } \\
& \text { Pseudo R }
\end{aligned}
$$

$\frac{\text { Earnings }}{\text { Wives } \text { Husbands }}$

(3)

(4)

$\begin{array}{cc}.482^{* * *} & 2026^{* * *} \\ (16.76) & (26.86) \\ -4,096^{* * *} & -18,437^{* * *} \\ (420) & (618) \\ 360 & 255 \\ (260) & (428) \\ 181 & -61.41 \\ (255) & (418) \\ 170 & -117 \\ (259) & (424) \\ -235 & 215 \\ (258) & (425) \\ -353 & 72.28 \\ (258) & (421) \\ -465^{*} & 159.99 \\ (257) & (421)\end{array}$

$(.002)$

$-.053^{* * * *}$

(.005)

\begin{tabular}{cc}
\multicolumn{2}{c}{ Log of earnings } \\
\hline Wives & Husbands \\
$(5)$ & $(6)$
\end{tabular}

(5)

(6)

$\begin{array}{cc}.009^{* * *} & .023^{* * *} \\ (.001) & (.0004) \\ -.067^{* * *} & -.245^{* * *} \\ (.016) & (.012) \\ .013 & .003 \\ (.010) & (.007) \\ .009 & .002 \\ (.009) & (.007) \\ .009 & -.008 \\ (.010) & (.007) \\ -.016^{*} & .005 \\ (.010) & (.007) \\ -.019^{* *} & .004 \\ (.009) & (.007) \\ -.021^{* *} & .008 \\ (.010) & (.007)\end{array}$


Table 6: Black married couples. Regressions of socioeconomic factors on own characteristics and spouse's quarter of birth indicators and socioeconomic factor.

\begin{tabular}{|c|c|c|c|c|c|}
\hline \multicolumn{2}{|c|}{ Education } & \multicolumn{2}{|c|}{ Earnings } & \multicolumn{2}{|c|}{ Log of earnings } \\
\hline Wives & Husbands & Wives & Husbands & Wives & Husbands \\
\hline (1) & (2) & (3) & (4) & (5) & (6) \\
\hline
\end{tabular}

\begin{tabular}{|c|c|c|c|c|c|c|}
\hline Age & $\begin{array}{l}.016^{* * * *} \\
(.004)\end{array}$ & $\begin{array}{l}.0027 \\
(.004)\end{array}$ & $\begin{array}{l}739^{* * *} \\
(65.4)\end{array}$ & $\begin{array}{c}866^{* * *} \\
(78.61)\end{array}$ & $\begin{array}{l}.022^{* * *} \\
(.002)\end{array}$ & $\begin{array}{l}.024^{* * * *} \\
(.002)\end{array}$ \\
\hline Hispanic & $\begin{array}{l}-.107 \\
(.142)\end{array}$ & $\begin{array}{c}.095 \\
(.164)\end{array}$ & $\begin{array}{c}4,602 \\
(3,209)\end{array}$ & $\begin{array}{l}-769.7 \\
(3,903)\end{array}$ & $\begin{array}{l}.167^{* * * *} \\
(.069)\end{array}$ & $\begin{array}{c}.029 \\
(.110)\end{array}$ \\
\hline $2^{\text {nd }}$ quarter of birth & $\begin{array}{c}-.018 \\
(.060)\end{array}$ & $\begin{array}{c}.084 \\
(.058)\end{array}$ & $\begin{array}{c}-1,167 \\
(900)\end{array}$ & $\begin{array}{l}-2,040 \\
(1,271)\end{array}$ & $\begin{array}{l}-.037 \\
(.034)\end{array}$ & $\begin{array}{l}-.010 \\
(.031)\end{array}$ \\
\hline $3^{\text {rd }}$ quarter of birth & $\begin{array}{c}.048 \\
(.057)\end{array}$ & $\begin{array}{l}.095^{*} \\
(.054)\end{array}$ & $\begin{array}{c}1,850^{* *} \\
(967)\end{array}$ & $\begin{array}{c}-633 \\
(1,280)\end{array}$ & $\begin{array}{c}.039 \\
(.033)\end{array}$ & $\begin{array}{c}.022 \\
(.030)\end{array}$ \\
\hline $4^{\text {th }}$ quarter of birth & $\begin{array}{c}.115 \\
(.059)\end{array}$ & $\begin{array}{c}.094 \\
(.057)\end{array}$ & $\begin{array}{c}1,154 \\
(1,002)\end{array}$ & $\begin{array}{c}-425 \\
(1,248)\end{array}$ & $\begin{array}{c}.028 \\
(.035)\end{array}$ & $\begin{array}{c}.016 \\
(.030)\end{array}$ \\
\hline $2^{\text {nd }}$ quarter of birth spouse & $\begin{array}{l}-.045 \\
(.060)\end{array}$ & $\begin{array}{l}-.011 \\
(.056)\end{array}$ & $\begin{array}{c}979 \\
(1,028)\end{array}$ & $\begin{array}{c}1,971 \\
(1,242)\end{array}$ & $\begin{array}{c}.050 \\
(.034)\end{array}$ & $\begin{array}{l}.045 \\
(.031)\end{array}$ \\
\hline $3^{\text {rd }}$ quarter of birth spouse & $\begin{array}{c}-.050 \\
(.058)\end{array}$ & $\begin{array}{l}-.030 \\
(.055)\end{array}$ & $\begin{array}{c}839 \\
(997)\end{array}$ & $\begin{array}{c}1,174 \\
(1,175)\end{array}$ & $\begin{array}{l}-.007 \\
(.035)\end{array}$ & $\begin{array}{c}.018 \\
(.030)\end{array}$ \\
\hline $4^{\text {th }}$ quarter of birth spouse & $\begin{array}{c}.009 \\
(.059)\end{array}$ & $\begin{array}{c}-.049 \\
(.056)\end{array}$ & $\begin{array}{c}1,633^{*} \\
(978)\end{array}$ & $\begin{array}{c}2,926^{* * *} \\
(1,280)\end{array}$ & $\begin{array}{c}.042 \\
(.034)\end{array}$ & $\begin{array}{l}.067^{* *} \\
(.031)\end{array}$ \\
\hline Education spouse & $\begin{array}{l}.563^{* * *} \\
(.011)\end{array}$ & $\begin{array}{l}.506^{* * *} \\
(.012)\end{array}$ & & & & \\
\hline Earnings spouse & & & $\begin{array}{l}.124^{* * *} \\
(.015)\end{array}$ & $\begin{array}{l}.199^{* * * *} \\
(.022)\end{array}$ & & \\
\hline Log of Earnings spouse & & & & & $\begin{array}{l}.214^{* * *} \\
(.017)\end{array}$ & $\begin{array}{l}.175^{* * *} \\
(.015)\end{array}$ \\
\hline $\mathrm{N}$ & 9,392 & 9,392 & 9,392 & 9,392 & 7,621 & 7,621 \\
\hline Pseudo $\mathrm{R}^{2}$ & .305 & .306 & .080 & .079 & .101 & .098 \\
\hline
\end{tabular}

Note. Omitted category is the first quarter of birth. Regressions include state and year fixed effects. Observations have been weighted by using person weights. Heteroskedasticity robust standard errors are reported in parentheses. *** p-value $<0.01, * * \mathrm{p}$-value $<0.05, * \mathrm{p}$-value $<0.1$. 
Table 7: White cohabiting couples. Regressions of socioeconomic factors on own characteristics and partner's quarter of birth indicators and socioeconomic factor.

$\frac{\text { Education }}{\text { Women Men }}$

\section{Age}

Hispanic

$2^{\text {nd }}$ quarter of birth

$3^{\text {rd }}$ quarter of birth

$4^{\text {th }}$ quarter of birth

$2^{\text {nd }}$ quarter of birth partner

$3^{\text {rd }}$ quarter of birth partner

$4^{\text {th }}$ quarter of birth partner

Education spouse

Earnings spouse

Log of Earnings partner

$$
\begin{aligned}
& \text { N } \\
& \text { Pseudo } \mathrm{R}^{2}
\end{aligned}
$$

(1)

$\frac{\text { Earnings }}{\text { Women Men }}$

(3)

(4)

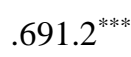

(60.23)

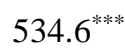

(80.94)

$-7,470^{* * *}$

(761.4)

$-8,194^{* * *}$

(995)

$1,432^{\text {** }}$

(609.7)

$1,446^{*}$

(920.4)

$1,303^{\text {** }}$

(607.9)

$-330.7$

$(822)$

1,010

(616.4)

772.7

(926)

$-51.43$

(613)

$-9.48$

(924)

928.2

(598)

$-797.1$

(849.5)

510.6

(645)

122.3

(851)

$.555^{* * *}$

$.571^{* * *}$

(.009)
Log of earnings

\begin{tabular}{cc}
\hline Women & Men \\
$(5)$ & $(6)$ \\
\hline
\end{tabular}

$\begin{array}{cc}.026^{* * *} & .007^{* * *} \\ (.002) & (.002) \\ -.177^{* * *} & -.221^{* * *} \\ (.033) & (.031) \\ .048^{*} & -.007 \\ (.025) & (.022) \\ .049^{* *} & .-014 \\ (.025) & (.022) \\ .032 & .004 \\ (.025) & (.023) \\ .038 & -.026 \\ (.024) & (.022) \\ 046^{*} & -.028 \\ (.024) & (.022) \\ .025 & .-001 \\ (.025) & (.022)\end{array}$

$\begin{array}{ll}.186^{* * *} & .352^{* * *} \\ (.012) & (.019)\end{array}$

Note. Omitted category is the first quarter of birth. Regressions include state and year fixed effects. Observations have been weighted by using person weights. Heteroskedasticity robust standard errors are reported in parentheses. $* * *$ p-value $<0.01, * * \mathrm{p}$-value $<0.05$, $* \mathrm{p}$-value $<0.1$ 
Table 8: Black cohabiting couples. Regressions of socioeconomic factors on own characteristics and partner's quarter of birth indicators and socioeconomic factor.

$\frac{\text { Education }}{\text { Women Men }}$

Age

Hispanic

$2^{\text {nd }}$ quarter of birth

$3^{\text {rd }}$ quarter of birth

$4^{\text {th }}$ quarter of birth

$2^{\text {nd }}$ quarter of birth partner

$3^{\text {rd }}$ quarter of birth partner

$4^{\text {th }}$ quarter of birth partner

Education spouse

Earnings spouse

Log of Earnings partner

$$
\begin{aligned}
& \text { N } \\
& \text { Pseudo R }
\end{aligned}
$$

(1)

$\frac{\text { Earnings }}{\text { Women Men }}$

(3)

(4)

$\begin{array}{cc}.591 .6^{* * *} & 359.1^{* * *} \\ (99.0) & (127.9)\end{array}$

$-1,439$

$(2,646)$

$-2,716$

$(2,868)$

$-1,512$

.012

.021

(117)

(.110)

$-.089$

(.117)

.016

(.100)

.010

(.126)

$-.100$

$-.058$

(.095)

(.126)

$-.107$

(.097)

$-.027$

(.114)

$$
-.023
$$

.140

(.121)

(.093)

$.533^{* * * *}$

(.028)

$-.011$

(.101)

$.372^{* * * *}$

(.023)

(1,371)

1,989

(1,643)

1,125

$(1,847)$

(1210)

732

$-233.4$

$(1,288)$

(1,619)

$-450.6$

2,508

$(1,479)$

$(1,801)$

$-1,804$

$(1,414)$

70.00

$(1,355)$

$-2,187$

$2,784^{*}$

$(1,457)$

$(1,645)$

$\frac{2 \text { Log of earnings }}{\text { Women }}$

(5)

(6)

$\begin{array}{ll}.169^{* * *} & .225^{* * *} \\ (.034) & (.033)\end{array}$

$.169^{* * *}$
$(.034)$

\begin{tabular}{|c|c|c|c|c|c|}
\hline & & & & $\begin{array}{l}.169^{* * * *} \\
(.029)\end{array}$ & $\begin{array}{l}.193^{* * *} \\
(.037)\end{array}$ \\
\hline 2,264 & 2,264 & 2,264 & 2,264 & 1,798 & 1,798 \\
\hline .234 & .225 & .107 & .088 & .122 & .113 \\
\hline
\end{tabular}

(.033)

Note. Omitted category is the first quarter of birth. Regressions include state and year fixed effects. Observations have been weighted by using person weights. Heteroskedasticity robust standard errors are reported in parentheses. $* * *$ p-value $<0.01, * * \mathrm{p}$-value $<0.05, * \mathrm{p}$-value $<0.1$.

$\begin{array}{lc}.029^{* * *} & .007 \\ (.005) & (.007)\end{array}$

$-.004-.084$

(.113) (.121)

$-.102 \quad .013$

(.071) (.091)

$\begin{array}{ll}-.004 & -.042\end{array}$

(.059) (.078)

$-.050 \quad-.076$

(.066) (.082)

$.034 \quad .144^{*}$

(.077) (.082)

$.051 \quad .168^{* *}$

(.069) (.077)

$-.053 \quad .134^{*}$

(.076) (.081) 